\title{
Lay expertise: Why involve the public in biobank governance?
}

\author{
BJØRN K. MYSKJA ${ }^{1}$
}

\begin{abstract}
Key to concerns about public involvement in technology governance is the concept of lay expertise, the idea that lay people possess some kind of special knowledge that neither trained experts in technology, ethics and social sciences nor professional politicians possess. There are at least four different meanings of "lay expert": (1) Lay people who are educated into quasi-experts on a particular issue or technology; (2) Lay people who turn themselves into experts in order to challenge scientific experts; (3) Lay people with particular knowledge based on tradition and experience; (4) Lay people who represent an alternative perspective to expert views because they are nonexperts. The challenge is that lay people are often ignorant in the relevant matters and wish to leave governance to experts. Still, there are normative reasons for lay engagement, either as stakeholders or as citizens in a deliberative democracy. According to the second approach, political decisions should be based on an inclusive open debate aimed at the better argument, providing lay people a crucial role in governance. In order to include lay people without making them hostage to experts, politicians or interest groups, we can engage them in focus group interviews which are analysed by social scientists and included in the interdisciplinary debate in journals and political forums.
\end{abstract}

\section{Introduction}

Today it is almost self-evident that lay people should be involved in the political deliberation on how to regulate applications of new technologies, such as genetic databases, usually called biobanks. In many other kinds of political controversy, most people tend to be satisfied that representative democracy guarantees legitimate decision-making, but in applications of new technologies, basing political decisions on best available scientific advice is not regarded as sufficient. We need to consult the general public to ensure that we reach the right decision. Frequently, even technologists engage sociologists to explore public opinions of their activities. This may be with a view to either exploring the viability of their planned product in the market or to find ways to pre-empt negative public reactions, but in many cases they talk as if the public assessment of the products has value in itself, not merely as a means for planning market strategies. Likewise, politicians speak of public consultations not merely as a way to gain popular support for their decisions but as public participation in governance. If the aim of involving the public had been merely adjustment of market strategies and policy to accommodate public opinion, using professional opinion pollsters would seem a better strategy than the expensive and elaborate consultation procedures that are often used.

The key to the increased concern with public involvement in technology governance is the concept of lay expertise, which expresses the idea that lay people possess some kind of special knowledge that neither trained experts in technology, ethics and social

Genomics, Society and Policy, Vol.3, No.1 (2007) ISSN: 1746-5354

(C) ESRC Genomics Network. 
sciences nor professional politicians possess. As Collins and Evans point out, "lay expertise" is an oxymoron; it is the expertise of not being an expert. ${ }^{2}$ The other expert groups mentioned above have particular training and practice that enable them to be experts, whereas lay people are given expert status due to their lack of such training and practice. It is easy to get the impression that it is ignorance that is their expertise that their particular kind of knowledge is lack of knowledge. As we have all other kinds of expertise involved in technology governance, we must also have the expertise of non-expertise represented. To avoid such paradoxical kinds of reasoning it is important to clarify the contributions lay people can provide that otherwise would not be represented in biobank governance. In what sense is there such a thing as lay expertise, and when is it needed? When we have answered these questions, we are in a better position for deciding how to engage lay people in order to bring out this kind of expert knowledge.

\section{The rise of lay expertise}

Lindsay Prior explores the emergence of the concept of "lay expertise" as connected to the "legitimation crisis during the late $20^{\text {th }}$ century" of medicine and other professional activities, which has lead to an interest in the particular knowledge lay people possess, as well as a "tendency to argue that lay knowledge can be every bit as valuable as professional knowledge." 3 Prior does not contest the value of lay experiences in understanding health issues, but doubts the suitability of calling this expertise. In health matters, lay expertise consists of experience, but "experiential knowledge is invariably limited, and idiosyncratic" and "lay people can be wrong." But expert knowledge is also limited and quite often wrong, too, so this cannot be sufficient evidence for discounting the notion of lay expertise. The idiosyncrasy or particularity of lay experience may not always be the drawback Prior implies. We know that testing general hypotheses on particular instances is the paradigmatic scientific exercise. Aristotle stresses that practical wisdom (phronesis) is not only universal knowledge, but as much about particular instances, and "some people who lack knowledge but have experience are better in action than others who have knowledge." Aristotle's emphasis on the value of experience is particularly relevant for inexact, interpretive areas of knowledge such as health issues or areas of significant complexity, which involve a wide range of different actors with incompatible values and interests. Needless to say, Prior recognises that lay people have important contributions to make, which supplement expert knowledge, and his critique of the way "lay expertise" has been used within sociology of health is reasonable. Still, some of the reasons for the paradoxical notion are missed if we accept his critique. I will explore the normative reasons for involving lay people in biobank governance through describing four different meanings of "lay expertise", and analyse what kinds of involvement the different understandings of the term imply.

\section{Lay expert I: The educated Rita}

In the movie "Educating Rita" we meet an ordinary working-class girl who wishes to enter the halls of higher learning and therefore enrols at the Open University. She succeeds in her endeavour but on the way she also discovers the hollowness of the knowledge that seemed so important to her. Some of the basic problems with

Genomics, Society and Policy, Vol.3, No.1 (2007) ISSN: 1746-5354

(C) ESRC Genomics Network. 
theoretical education of people with rich experiential knowledge raised by this movie are echoed in the first understanding of "lay expertise"; the education of lay people into quasi-experts on a particular issue or technology. People with a generally accepted expert status teach lay people how the technology works, what resources it demands, the associated benefits, risks and uncertainties, as well as what and who are affected by the technology. As we see from this open-ended list, different kinds of experts are needed to educate lay people.

Typical examples of the kind of educational processes that create lay experts are the consensus conference and the citizen's jury, but other expert-dominated consultation approaches serve the same purpose. ${ }^{6}$ A consensus conference involves a lay panel of 10 to 14 interested lay people with varied socio-demographic backgrounds, who are not interested enough to have expert knowledge on the relevant issues. They are given background reading material and then gathered for discussions with, and provided information by, a wide range of experts. A list of potential experts is drawn up by the expert-based steering committee, the lay panel suggests who they want to invite, but the committee has the final word on who will actually appear. ${ }^{7}$ This is reasonable, considering that it is difficult for non-experts to recognise who is an expert; it takes one to know one. The final result of the conference is a document, preferably without dissenting opinions, where "argumentative evaluations and recommendations are given by the lay panel on the measures called for in the various fields covered by the topic." 8 The objective of this "fairly complicated method of technology assessment" is "to bridge the gap between the general public, experts and politicians", to engage public and experts in dialogue, and the Danish Board of Technology

is convinced that the process is fruitful and that it contributes to the general public's and politician's acknowledgement of the necessity for increased understanding of and participation in the debate surrounding new technology.

The lay people selected for the panel are given prior information enabling them to enter into a dialogue with experts and, on this basis, to make recommendations to politicians. One interesting question regarding this version of lay involvement is why lay people rather than the experts themselves should evaluate and recommend political measures, given that the experts are the ones with knowledge which provide basis for the evaluations. Does the lay panel recommend different measures than the experts would? It is unlikely that their conclusion is different from the recommendations of all the experts, since the expert group includes a diversity of views, and studies of the citizen's jury approach show lay recommendations being "remarkably close" to the expert advice. ${ }^{9}$ As there is a strong pressure towards consensus in the lay panel, we can assume a conservative bias in their policy recommendations. It is easier to agree on keeping things as they are than to agree on untried changes with far-reaching consequences, especially if one is not an expert on the issue and must choose to trust one or a few of several apparently very competent people with diverging views.

Irrespective of the correctness of this assumption about a conservative bias, we may still ask why it is important that the lay panel does not have any strong prior knowledge or represent any particular interest group involved in the issues under

Genomics, Society and Policy, Vol.3, No.1 (2007) ISSN: 1746-5354

(C) ESRC Genomics Network. 
discussion. The reason seems to be that lay people see problems and solutions that the experts miss. They are not immersed in a particular way of perceiving the world, and are free of some prejudices or ground assumptions that are part of the scientific education and training. As the lay people are presented with these differing views as seen from within the expert culture, the assumption seems to be that they are able to evade being drawn into the scientific mindset and keep their outsider perspective while they learn from the experts. This is of course very optimistic and quite contrary to the message of "Educating Rita": gaining new knowledge implies as much learning a new way to regard the world. Kerr et al describe how several lay consultations of this kind turned into events where

The selection of speakers and the format of speaker-audience interactions are obvious ways in which expert positions were privileged, even when space was made for lay contributions from the podium or the floor. ${ }^{10}$

Thus the educational model of lay expertise exemplified in consensus conferences and similar approaches may mean that we lose the most valuable contribution of lay people, namely lay independence from the expert's perspective and thereby their ability to serve as a corrective to this perspective.

\section{Lay experts II and III: The autodidact and the sage}

Consensus conferences exclude people with a particular interest in the issues at stake, and thus had acquired more than ordinary knowledge of those issues. But it is strange to avoid lay people that "can (and sometimes have to) turn themselves into experts in order to challenge medical hegemony." 11 The crucial difference between these autodidact experts and those who are trained in the consensus conference process is that the autodidacts have themselves decided what knowledge they need and where to find it. Thus they may be driven by exactly those particular values and perspectives that distinguish them from the expert culture, ie, the way of seeing that may function as a corrective to that of the experts. One example of an influential group of autodidacts in the genetics debate is members of the disability movement, who have had significant impact. ${ }^{12}$

As we know both from science and arts, this is a risky way to gain knowledge, due to the lack of correction from a community of peers, especially in an age of increasingly complex and specialised knowledge, with a wide array of information and disinformation available on the internet. In addition it is a fact that in areas of technology governance, expertise requires not only theoretical knowledge but also extensive practical training. Understanding the issues at stake in the establishment and use of genetic databases requires working knowledge of medical diagnostics, genetics, epidemiology, bioethics, sociology and anthropology. And "for most parts, lay people are not experts", ${ }^{13}$ at least not to this degree. The same can be said about philosophers, sociologists and most of the others who participate as experts in the biobank debate and other complex issues, because their expertise is restricted to particular aspects of the issue under discussion. But they have a clearly delimited area of expertise, and are recognised by their peers and the society at large as experts. Lay people must prove their expertise, and the only people who can judge whether they 
actually have the required degree of specialised knowledge are the recognised experts. Collins and Evans call these scientists who are "deeply involved in experimentation or theorization" the core-scientists, ${ }^{14}$ but later expand this group to include those whose "expertise would be continuous with the core-set's expertise", ${ }^{15}$ which makes it possible to include the autodidact as well as the lay expertise of the sage.

"The sage" is a stakeholder who has particular experientially based knowledge. These lay people are often portrayed as wise old men or women, but this group includes any lay person who is affected in a particular way by the technology in question and who possesses relevant knowledge connected to the way they are affected. In this case it is not a matter of regarding the same facts differently from the core-scientists but of having experience-based supplementary knowledge beyond the common knowledge of the relevant society. This knowledge can be acquired in many different ways, as long as the main element is non-theoretical. A prime example is the Cumbrian sheep farmers as Wynne contrasts them with the scientific experts in the management of the effects of the Chernobyl disaster. He describes how

the farmers felt that their whole identity was under threat from outside interventions based upon what they saw as ignorant but arrogant experts who did not recognize what was the central currency of the farmer's social identity, namely their specialist hill farming expertise. ${ }^{16}$

Collins and Evans understand Wynne's distinction between scientific and lay expertise as one between two different kinds of knowledge in need of translation by someone with "interactional expertise" in order to gain a higher level of combined knowledge. ${ }^{17}$ This understanding of this kind of non-expert knowledge, as a unique source of knowledge that can and should supplement the scientific expert knowledge as equally valuable, is a common one. Wynne, however, goes one step further. By juxtaposing the farmer's practical expertise based on socially and experientially acquired knowledge with the scientist's theoretically-based knowledge, Wynne paints a picture of a flexible and reflexive knowledge system accepting intrinsic uncertainty and ignorance quite different from a science driven "towards unrealism, insensitivity to uncertainty and variability, and incapable of admitting its own limits". ${ }^{18}$ In reply to Collins and Evans, Wynne rejects their reading of his study as revealing two compatible sources of propositional knowledge. We should not include lay opinion in order to supplement scientific expertise with an equally important form of expertise in order to get a better and more complex understanding of the issue. The lay expertise of the sheep farmers represented an alternative to the scientific understanding of what was at stake in the aftermath of the Chernobyl radioactive pollution. ${ }^{19}$ The Cumbrian sheep farmers as understood by Collins and Evans are representatives of "the sage" lay expertise, whereas Wynne's own understanding of their role in public debate points out a fourth understanding of the term. I return to this below.

The autodidact and the sage are two different, but related lay experts. They are themselves in control of where to acquire their knowledge and how to use it, unlike the "educated Rita", and they play the role of alternative voices to the science experts. This lay expertise is the kind that is often sought in sociological and ethical studies of science, by surveys and focus group interviews, as well as in the consultation kind of 
public engagement, such as has been held for the proposed UK Biobank. ${ }^{20}$ The expertise sought in these contexts may be deemed valuable and interesting in some cases where they have genuine contributions. In medical diagnostics, the patient is an expert on his own story, just as the Cumbrian farmers knew the patterns of rainfall and how the sheep grazed on the hillsides of the Lake District. The patient with a particular difficult inherited disease may read advanced medical literature about his own condition and combine it with observations, in order to know more both in theory and practice about his own condition than most of the specialists he encounters. Still, these lay experts play on the scientists' field, and the soundness of their expertise is judged according to how it fits in with the scientific "core-set" expertise. Thus, conceived in this way, lay expertise can only challenge scientific expertise on details within the scientists' own language and world-view, but cannot question that worldview itself. Collins and Evans argue that lay people with experiential expertise should retain an expert status, whereas Prior seems to think lay people have even less to offer when he suggests it is

time to recognise the virtues of expertise, and not to confuse issues concerning the use and manipulation of technical knowledge (the realm of expertise) with the worthy political aim of ensuring participation and consultation of the lay public in all matters to do with medicine. ${ }^{21}$

Both articles fail to present a view of lay experts as people who are able to raise an alternative to the scientific world-view. Their expertise is merely an appendix to the scientific expertise, and it is not regarded as independent of the perspective already accepted in the scientific world-view. From the history of science we know that one of the primary strengths of science is its anti-dogmatic approach, including a systematic openness to internal and external criticism. The most interesting kind of lay expertise is the one that can serve as a corrective to the accepted views of science, exposing its limits as well as its strengths. This is of course something both the autodidact and the sage can do, but not within the framework envisaged by Prior or Collins and Evans, however right they may be in their implicit claim that science is our primary source of knowledge. To capture this potential strength of lay knowledge, we must regard it as an independent source of knowledge, as something independent of the approach of experts.

\section{Lay expert IV: The clear-sighted}

"Lay expert" appears to be an oxymoron, but in a society with a growing class of highly educated specialists, a significant proportion of the citizens can be regarded as experts in particular fields of knowledge. In addition, experts play an increasingly active role in a number of areas in society, giving advice both in professional as well as in private life. The expert has become a common part of public life, not an outsider that gets involved merely in extraordinary circumstances of problem-solving. In such a society the lay person is not merely negatively defined as someone who lacks a particular kind of competence, but rather as someone who stands outside and inhabits the common world of human experience, where expert knowledge is a particular, privileged form of experience. Thus the lay person has a particular kind of experience 
that the expert cannot have; namely access to this non-specialised perspective on the issue. Here lay expertise is the expertise of not being an expert.

One well-known example of this kind of expertise is the one demonstrated by the little child in H. C. Andersen's fairytale "The Emperor's New Clothes". In this story, the Emperor is tricked by two conmen into believing that they made the most exquisite clothing of a garment that is invisible to those who are stupid or unsuitable for their office. Nobody would admit that they did not see the clothes when the emperor wore the non-existing clothes through the town, except a little boy who exclaims that the emperor has no clothes. ${ }^{22}$ The child is not mislead by the accepted perspective on things and is able to see the events with fresh eyes. I want to stress that I do not think that the scientific culture ever leads us into the kind of misconceptions described in Andersen's fairytale, but science can be corrected by someone who has less formal training and a different approach to the issue. Such lay experts serve the role of the clear-sighted, because they are able to "see" the world differently so as to correct the scientific view. Calling them "clear-sighted" does not imply that lay people usually are right, but to indicate their potential corrective role.

There is a long tradition of contrasting formal training with common sense, showing how the sound understanding of ordinary people is superior to the rigid and narrowminded formalism of academic expertise. Even the story told by Wynne belongs to this genre; the reflexive farmers who realise the limits of both their own and the experts' knowledge versus the arrogant and inflexible expertise:

The scientists on the other hand were expressing and reproducing their intellectual-administrative framework of prediction, standardization and control, in which uncertainties were 'naturally' deleted, and contextual objects, such as the farmers and their farms, were standardized and 'black-boxed' in ways consistent with this cultural idiom. Whatever private awareness they may or may not have had of the cultural limits and precommitments of their science, they successfully suppressed these. ${ }^{23}$

This should not be read as a rejection of scientific expertise, but as an attempt at describing its limitations. The central concept for the understanding of the lay expert as clear-sighted is common sense. Science is methodologically restricted, whereas common sense draws on feelings, judgements and reasoning in combination, and cannot be precise in the way science is. The scientific method gives reproducible results and is generally applicable, while common sense is able to disclose particular instances as well as complexities that escape the generalising methodology of science. This enables non-experts to see aspects of reality or ask questions that are closed to the scientific expertise.

Lay people's concerns must, however, be made accessible to the policy makers as well as to the scientific expertise in order to have an impact. Collins and Evans ${ }^{24}$ are right in pointing out the necessity of translation in order to establish well-functioning communication between the different groups involved in technology governance. Involving lay people not as experts continuous with science experts, but as an alternative corrective, enable us to tap into a different kind of knowledge and experience. They are, in a sense, untainted by scientific knowledge and culture, and 
can provide a different perspective from the ones presented by diverse expert groups. Therefore they are able to draw on traditional sources of knowledge and produce fresh analogies with everyday cases in the way that we who have this kind of systematic knowledge are unable to. It is this kind of "clear-sighted" lay expertise that is most interesting when discussing why, and in what way we should involve lay people in biobank governance.

These four versions of lay expertise are partly overlapping, but there are distinct differences indicating how we value lay contributions to the debate. But to know which approach we should take to lay involvement, we must determine why lay people should be involved. In the biobank debate we primarily need lay people to provide an outsider perspective, in order to raise the discussion at a more basic level, considering what kind of society, health service and medical research we want, and how genetic databases are conducive to these overarching goals.

\section{Ignorance as expertise?}

A fairly common view among scientists and other experts is that lay people present not as much an alternative understanding of reality as a misunderstood understanding of reality, and we have good reason to investigate this possibility closer. ${ }^{25}$ Unlike the picture painted by Wynne and others, one can argue that lay people are not more reflexive and responsive to the limits of their own understanding than scientists, but build their opinion on ill-informed prejudices and mistaken assumption. They can be just as unaware of their cultural limits as the scientists, as well as obviously wrong in their beliefs. I will modify this picture later, but if we first take a look at some of the support for this lay ignorance approach, we find one example among the early 'consultations' preparing the establishment of the UK Biobank:

The use of human biological samples in genetics research is less readily accepted, largely because genetics and genetics research are much misunderstood and have many unhelpful (and ill-informed) associations. There is a case for informing the general public about genetics research as well as its applications, particularly in relation to disease specific research, and its preventative potential. ${ }^{26}$

A classic example of lay ignorance of technology issues is found in the series of Eurobarometer-surveys on public conceptions of biotechnology from 1996 to 2002, which showed that a stable one-third of the European population agreed to the statement: "Ordinary tomatoes do not contain genes, while genetically modified tomatoes do". ${ }^{27}$ Admittedly, the large number of wrong answers can partly be due to misunderstandings of the question rather than ignorance, but still there is a case for claiming that lay people often misunderstand central issues because they lack the training that enable them to grasp the scientific and technological facts. ${ }^{28}$

But lay people are neither more nor less stupid than experts and many admit that they have this insufficient grasp, as a man from Manchester expressed when discussing the role of lay people in the Oversight Body of the UK Biobank: "I wouldn't have a clue what's going on". ${ }^{29}$ Most of the participants in this consultation found a role for lay participation in the body but emphasised the need for "professional people, who know 
what's going on". ${ }^{30}$ This is supported by statements from other surveys of people participating in existing biobanks, such as a Swedish one in Umea ${ }^{31}$ and the Norwegian HUNT Biobank. ${ }^{32}$ Similar results are also reported from research on blood donors to genetic research in the $\mathrm{UK}^{33}$, but it is important to stress that these studies do not show a lack of ability to understand, only that these respondents find this knowledge unnecessary or irrelevant. To summarise the findings: (1) Lay people often have insufficient knowledge to understand the issues at stake; (2) they know that they have this insufficient grasp; (3) they accept their insufficient knowledge. Many lay people prefer that trustworthy experts govern the activity, rather than leaving responsibility with lay people. Few lay people wish to go through demanding learning processes in order to gain sufficient understanding as long as they trust the people in charge of the activity.

This humility may seem to contradict Wynne's account of the Lake District farmers who disagreed with the expertise and questioned their competence. However, if we look closer at the different accounts, we find that the similarities are as significant as the differences. In both cases we find lay people who reflect on the limits of their own knowledge, and who express awareness of the uncertainties of human existence. The main difference is that the participants trust the Scandinavian biobanks because they are represented by people they trust and because the activity is regulated by authorities they trust. The trust is not built on information and consent, but rather on the relation between the participants and the representatives of the research activity, be it a nurse, a doctor or a researcher. In Wynne's account distrust replaces trust, but his study also emphasises the significance of the relation between lay people and experts:

Trust, or trustworthiness, and credibility are relational terms, about the nature of the social relationship between the actors concerned. They are not intrinsic to either actor nor to the information said to be transmitted between them. ${ }^{34}$

The sheep farmers had experience-based reasons for distrusting the scientists, and to seek their own understanding of the issues at stake. In a world where the experts established a good relationship with the farmers by listening to their concerns and expressing humility as to the predictive quality of their own approach, a more trusting relationship would probably ensue. It is not an inherent trait of science to be arrogant and dogmatic; it is merely a part of some pockets of scientific culture. Also, the farmers were aware of their own ignorance just as the biobank donors were. Such reflection on one's own ignorance is a central part of their kind of competence, but unlike the Scandinavian lay people, they also possessed unique expertise connected to their own life and profession. But in matters of biobank research, we seldom find the "sage" kind of lay expertise, because the issues are not local but general, and understanding them apparently requires a certain degree of academic training.

So, if biobank governance involves lay people who discuss from a position of ignorance and know that they expose their ignorance when they participate, they will neither be heard nor respected. This is hardly a good model for governance, and we would be better off with a well-functioning technocracy consisting of trustworthy experts. The Norwegian HUNT Biobank is an interesting case in this respect. It is

Genomics, Society and Policy, Vol.3, No.1 (2007) ISSN: 1746-5354

(C) ESRC Genomics Network. 
locally run and the participants from the Nord-Trøndelag county have a high degree of trust in the local researchers and the Norwegian regulation of research. They have no need to participate in governance of the biobank research as long as they see their interests being taken care of by trustworthy professionals and regulatory systems. But we know that such trust is fragile and only one scandal is sufficient to destroy it. Involving lay people can be seen as a preventive measure to ensure the stability of trust, on a par with other trust-supporting strategies such as openness and accountability. ${ }^{35}$ It turns out that the moment lay people cease to trust the experts, they are not as ignorant as they themselves and some scientists hold. This is expressed by a supporter of the participation of lay people in the Biobank Oversight Body:

I think sometimes medical people and scientists can get lost in a little world of their own without getting their feet on the ground. Maybe someone could hold them down on the ground a bit and show how it affects normal folks. ${ }^{36}$

What is expressed here is the role of lay people as clear-sighted articulators of common sense, as a watch-dog against technocratic excesses. They do not have to have specialised knowledge in epidemiology or genetics to have a role to play in biobank governance. Quite the contrary: they should not have any such expertise in order to play their role. Only then are they able to provide correctives to the scientists' tendencies to getting lost in their own perception of the world.

\section{Normative arguments for lay participation}

If we look for normative reasons for engaging lay people, at least two different lines of argument have been central to the debate. The first one holds that anybody who is affected by a proposed activity should have a say in the regulation of this activity. They should be heard because they are stakeholders. Ravet ${ }^{37}$ starts with the fact that in normal scientific activity we require that projects are subject to scientific peer reviews in order to secure acceptable quality. The case is different when the scientific activity is moved out of the laboratory into the complex physical and social reality beyond controlled experiments. Under such conditions we have what he calls "postnormal science", an activity where "facts are uncertain, values in dispute, stakes high and decisions are urgent" and we need an extended peer review, involving representatives of all affected parties. ${ }^{38}$ It is a sound moral principle that those who are affected by planned activity should take part in deciding how the activity should proceed, as long as they are capable of deciding what is best for them. This principle is supported both by deontological and by utilitarian arguments. ${ }^{39}$ For Ravetz, the reason for including lay people is not primarily ethical, but a matter of securing scientific quality in a state of scientific uncertainty. The scientists cannot achieve the ideal of value-free science, as is commonly pointed out in literature on the sociology of science, and therefore they will always be influenced by particular commitments and interests. Thus the debate of the 'extended peer community' aims to disclose such interests:

Since uncertainty cannot be tamed by statistical techniques whose value-commitments are concealed, debates will explicitly involve the participants' different agendas and perspectives. 
In this way experts and lay participants can engage in a process of mutual learning, which is the best way to reach good scientific quality, according to Ravetz.

This approach also illustrates some of the problems of stakeholder models for public engagement in that a stakeholder is someone with interests to protect in particular matters. The approach implies that the more affected a person is, the stronger his claim on a decisive voice in the proceedings is. The core of his participation is not as an expert with particular knowledge, but as one who is representing his own interests in an interest-based discussion. But such discussions are generally more directed at negotiations and compromises than at finding the best solution for society at large. There is also greater risk of insoluble value conflicts because different interests are supported by different kinds of values, as was demonstrated in the communication between the scientists and the sheep farmers in Wynne's account. Then we get politicisation of science with negotiations between different interests and values where the political strength of the participants becomes crucial for the outcome. Even if the stated aim of stakeholder involvement is trust based on respect, it is in reality a conflict-based model. The legitimacy and stability of decision depends on the stability of the power relations.

In Ravetz's model, we as citizens are holders of certain rights that we can promote in the extended peer review process, which is, therefore, a liberalistic model. The alternative, the deliberative democracy approach, points in a more republican direction. Policy should be built on public deliberation where the fundamental demand is that opinions should be supported by reasons.

The reasons that deliberative democracy asks citizens and their representatives to give should appeal to principles that individuals who are trying to find fair terms of cooperation cannot reasonably reject. ... They are reasons that should be accepted by free and equal persons seeking fair terms of cooperation. ${ }^{4}$

The normative basis for the requirement is that people should have the right to take part in the governance of society in order "to produce a justifiable decision and to express the value of mutual respect". ${ }^{42}$ But this requires that the reasons given are presented publicly and that they are accessible to everybody in the sense that they should be able to understand the reasons even if they fail to agree with them. The debate itself should be open-ended; even binding decisions "must be open to challenge at some point in the future". ${ }^{43}$ Unlike the stakeholder approach discussed above, the focus of the debate is not the political struggle to preserve one's own interests but the provision of arguments that are convincing also to others who have diverging interests to protect. Thus we aim for the better argument in a common pursuit of the good, not merely the arguments that support our own causes. Policy decisions should be based on an open public discussion where we recognise that there is a plurality of values in society and where we have mutual respect for each other's deliberative capacity. We do not know who is going to present the decisive arguments and the aim of this discussion is to get the best argument as basis for policy decisions. In this context lay people are regarded as equally rational to the experts although they are informed by other values and viewpoints. People should participate in governance, 
ie, public debate leading to policy decisions, because their contribution is of value for society.

The fundamental normative ideal underlying the deliberative democracy approach is deontological, emphasising respect for the unique value of every human being. This ideal is expressed in the absolute rejection of coercion and deception of others, as well as in regarding the communicative community as the final court of decision in moral and political matters. ${ }^{44}$ On the surface, one could think that even utilitarian reasoning could support a deliberative democracy approach because the goal of the deliberation is finding the common good. Of course, it is debatable whether an approach presupposing freedom and equality for every human being is compatible with utilitarian thinking, ${ }^{45}$ but regardless of that question there is a significant difference in that the procedure rather than the substance is crucial in a deliberative democracy approach, as it is in deontology. In utilitarianism, the criterion for deciding the value of a course of action is the overall consequences. If it contributes to general wellbeing, the act is morally good. Contrast this with the deliberative democracy approach where the criterion is whether everybody has been able to participate in the debate, indicating that the goal is part of the deliberation - together with the debate on how to reach this goal. The right course of action is the one that is determined through the right procedure, not the one that is determined by a particular principle. This parallels the Kantian determination of the form of the rule as determining its morality rather than the content. ${ }^{46}$

The deliberative democracy approach is procedural, and even if we disagree with the actual conclusion of the deliberation we can still accept the result as the outcome of a fair and reasonable procedure where everybody is given equal opportunity to influence the outcome by participating in deliberation. It is easy to engage experts and politicians in public deliberation on technology regulation, whereas lay people are more reluctant, due to their lack of technical knowledge of the issues involved as well as of the relevant laws and regulations. But if only decisions based on open and inclusive public debate are ethically legitimate, lay people should participate in these deliberations. This is not because we want them to protect their own interests and values, but in order to include their perspective and understanding of the situation. Then their values are included in the discussion as part of a common pursuit of the best understanding of the issues at stake, and not as a part of political negotiations between parties with diverging interests. This approach includes the stakeholder perspective, but directs the attention away from lay people as representing interests, and towards lay people as providers of valuable knowledge and alternative worldviews. It is closer to Wynne's understanding of the lay expert as someone who can raise a fundamental discussion of ethical worldviews than to Collins and Evans's notion of lay people as supplementing the core expertise. In biobank governance where everybody is a stakeholder, seeking alternative understandings of how society should relate to new technological opportunities should be the main reason for including lay people.

The deliberative democracy approach shares one crucial weakness with the stakeholder approach, a weakness that is a fundamental challenge to technology governance: lay people rarely wish to participate. Why should they participate in this 
discussion? Most people want to participate when they see that there is something at stake for them, but the issues concerning biobank regulation are vague and technically complicated, lacking any clear relevance for the public. Some engaged citizens will probably participate because they wish to learn more, and others belong to patient activist groups and other NGOs with a considerable degree of knowledge and a wish to influence policy. These groups will usually fall into the Educated Rita and the Autodidact categories respectively. Since the main aim in this context is to decide how to bring into play the knowledge resources of the expertise of not being an expert, the Clear-sighted, we aim for engaging those who initially do not want to get engaged. Obviously they will not see how they themselves could contribute to regulation of issues that they have no particular wish to understand. Both motivation and information are lacking.

If we accept this description, the question is what kind of lay involvements will motivate and bring out the alternative perspectives of the "lay expert". As already indicated, the kind of consultation processes found in consensus conferences, citizen's juries and open meetings have some fundamental weaknesses, as they are often dominated or even manipulated by organisers, experts, or activists, even if these consultation methods may have other valuable aspects. We should keep in mind that whatever way we organise lay involvement, the important work is not done in the consultation process itself, but in the informed debate leading to political decisions, and it is contributions to this debate we aim for. Perhaps the best approach is focus group interviews or similar approaches, such as the Democs card game. ${ }^{47}$ These more or less open interpersonal engagement methods may be followed up by more structured individual interviews in order to elaborate interesting ideas. Lay people, especially those who are reluctant to participate in a debate because they regard themselves as ignorant of the biobank issues, can be reached in these kinds of approaches. The main benefit of such engagement processes is that the participants will only be discussing with their peers, and need not fear appearing as ignorant. Then one can create the ideal conditions for bringing out alternative perspectives on issues relating to biobank governance.

Creating debate between people with similar backgrounds may also be a way to benefit from the group polarisation phenomenon, ie, that "members of a deliberating group predictably move towards a more extreme point in the direction indicated by the members' predeliberation tendencies". ${ }^{48}$ Shakespeare, Scully and Banks illustrate the positive effects of using focus groups with follow-up interviews among nonexperts in their ongoing Ordinary Ethics project, which studies opinions on prenatal sex selection. They are able to draw out interesting arguments countering the dominant bioethics expert views:

Most had a very strong intuition about it at the start of the discussion, and very few changed their mind. What the group discussion enabled them to do was to clarify and articulate their moral reasoning behind their intuition. Importantly, we have been able to show that public responses to these issues are not based on unthinking, knee-jerk prejudice. Lay people use a variety of evaluative approaches and moral resources, including personal experience, analogies with similar situations, and hypothetical reasoning. ${ }^{49}$ 
Levitt and Weldon emphasise that focus group interviews can "provide the context or personal history of people's responses" which is particularly important for privacy and trust, key issues in the ethics of biobanking. ${ }^{50}$ In addition, this approach enabled them to "explore how people use their existing knowledge to make sense of a new issue." $" 51$ One could argue that the issues that were of concern for the participants in this study are ones already present in the debate, such as genetic exceptionalism, privacy, commercialisation, containment of information flow and potential for harm, making lay contribution superfluous in biobank governance. But that is not the case, as the lay people had their own approach to issues such as research priorities, funding and who should benefit from this kind of research. Their concern was not primarily individualistic, as the expert debate focussing on informed consent tends to be, showing that this kind of lay engagement provides an alternative perspective valuable to the debate. ${ }^{52}$

These opinions provide background material for the informed discussions in scientific journals and in the political debate. The aim is to have informed discussion where lay opinions are included in a language that makes an impact. This requires a translation and clarification of the lay position as demonstrated in several of the studies discussed here. Such presentation of lay perspectives requires both competence in analysis of interview material and willingness to be informed by non-experts.

\footnotetext{
${ }^{1}$ Department of Philosophy, NTNU Trondheim, Norway bjorn.myskja@hf.ntnu.no

${ }^{2}$ H.M. Collins and R. Evans. The Third Wave of Science Studies: Studies of Expertise and Experience. Social Studies of Science 2002; 32: 238.

${ }^{3}$ L. Prior. Belief, knowledge and expertise: the emergence of the lay expert in medical sociology.

Sociology of Health \& Illness 2003; 25: 43.

${ }^{4}$ Ibid, p.53.

${ }^{5}$ Aristotle. 1985. Nicomachean Ethics. Indianapolis. Hackett: $1141 \mathrm{~b} 15$.

${ }^{6}$ Three different approaches with similar effects on the lay-expert interaction are discussed in A. Kerr, S. Cunningham-Barley and R. Tutton. Shifting Subject Positions: Experts and Lay People in Public Dialogue. Social Studies of Science 2007; 37 (3): 385-411.

${ }^{7}$ J. Grundahl. 1995. The Danish Consensus Conference Model. In Public participation in science: the role of consensus conferences in Europe. S. Joss and J. Durant, eds. London. Science Museum. ${ }^{8}$ Ibid.

${ }^{9}$ A. Kerr and S. Cunningham-Burley. On Ambivalence and Risk: Reflexive Modernity and the New Human Genetics 2000; 34 (2): 293

${ }^{10}$ Kerr et al, op.cit. note 6, p.407.

${ }^{11}$ Prior, op.cit. note 3, p. 45 .

${ }^{12}$ Kerr and Cunningham-Burley, op.cit.note 9.

${ }^{13}$ Ibid.

${ }^{14}$ Collins and Evans, op.cit. note 2, p.242.

${ }^{15}$ Ibid, p.252.

${ }^{16}$ B. Wynne. Misunderstood misunderstanding: Social identities and public uptake of science. Public. Understanding of Science 1992; 1: 295.

${ }^{17}$ Collins and Evans, op.cit. 2: 257.

${ }^{18}$ Wynne, op.cit. note 16, p.294.

${ }^{19}$ B. Wynne. Seasick on the Third Wave? Subverting the Hegemony of Propositionalism: Response to Collins \& Evans (2002). Social Studies of Science. 2003; 33 (3): 401-417.

${ }^{20} \mathrm{http}: / /$ www.ukbiobank.ac.uk/ethics/consult.php (accessed 22.06.2007)

21 Prior, op.cit. note 3, p.54.
} 
${ }^{22}$ This metaphor for describing non-expert corrective of science is also used in S. Jasanoff. Breaking the Waves in Science Studies: Comment on H.M. Collins and Robert Evans, The Third Wave of Science Studies. Social Studies of Science 2003; 33(3): 398.

${ }^{23}$ Wynne, op.cit. note 16, p.298.

${ }^{24}$ Collins and Evans, op.cit. note 2, p.257.

${ }^{25}$ This 'knowledge deficit model' has been studied and criticised in a large number of papers, eg, C.G. Brunk. Public Knowledge, Public Trust. Understanding the 'Knowledge Deficit Model'. Community Genetics. 2006: 9 (3): 178-183.

${ }^{26}$ Cragg Ross Dawson. Public Perceptions of the Collection of Human Biological Samples. Report. London. The Wellcome Trust and The Medical Research Council. 2000: 15. http://www.ukbiobank.ac.uk/docs/perceptions.pdf (accessed 22.06.2007). It should be emphasised, however, that a much more nuanced picture of public understanding of biobank research issues is drawn in other parts of the UK Biobank consultation documents.

${ }^{27}$ G. Gaskell, N. Allum and S. Stares. Europeans and Biotechnology in 2002. Eurobarometer 58.0. 2003: 20. http://europa.eu.int/comm/public_opinion/archives/eb/ebs_177_en.pdf (accessed 08.03.2007)

${ }^{28}$ There are differences between lay people regarding their wish and ability to grasp scientific knowledge, but relatively few can draw on complementary expertise such as the citizen's jury spokeswoman described by Kerr et al, op.cit. note 6, p.395.

${ }^{29}$ People Science \& Policy Ltd. UK Biobank Consultation on the Ethical and Governance Framework. Report prepared for The Wellcome Trust and The Medical Research Council. 2003. London: 4. http://www.ukbiobank.ac.uk/docs/people-science-policy.pdf (accessed 22.06.2007).

${ }^{30}$ Ibid, p.3.

${ }^{31} \mathrm{~K}$. Hoeyer. 'Science is really needed - that's all I know': informed consent and the non-verbal practices of collecting blood for genetic research in northern Sweden. New Genetics and Society 2003; 22 (3): 229-244.

${ }^{32}$ J.-A. Skolbekken. Not worth the paper it's written on? Informed consent and biobank research in a Norwegian context. Critical Public Health 2005; 15 (4): 335-347.

${ }^{33}$ H. Busby. 2004. Blood donation for genetic research: What can we learn from donors' narratives?. In Genetic Databases: Socio-ethical issues in the collection and use of DNA. R. Tutton and O. Corrigan, eds. London. Routledge: 39-56.

${ }^{34}$ Wynne, op.cit. note 12, p.282.

${ }^{35}$ O. O’Neill. 2002. Autonomy and trust in bioethics. Cambridge. Cambridge University Press: 129.

${ }^{36}$ People Science \& Policy Ltd., op.cit. note 29, p.5.

${ }^{37}$ J. Ravetz. The Post-Normal Science of Precaution. Futures 2004; 36.

${ }^{38}$ Ibid, p.349.

${ }^{39}$ The Categorical Imperative, the basic expression of the deontological moral law, states that one should never treat a human being as a mere means, but also as an end in itself (I. Kant. 1965. Grundlegung zur Metaphysik der Sitten. Hamburg. Felix Meiner Verlag: 52). Letting the affected people take part in deciding how an activity that influences their lives should be conducted is the best way to treat them as ends. According to the Utilitarian Principle, an act is right when it increases overall welfare (J.J.C. Smart and B. Williams. 1973. Utilitarianism: For or Against. Cambridge. Cambridge University Press: 4.) But is there a better judge of a course of action that will contribute to a person's own welfare than the person affected by it, given that they are competent?

${ }^{40}$ J. Ravetz, op.cit. note 37, p.351.

${ }^{41}$ A. Gutmann and D. Thompson. 2004. Why Deliberative Democracy? Princeton. Princeton University Press: 3.

42 Ibid, p.4.

${ }^{43}$ Ibid, p.6.

${ }^{44}$ O’Neill. op.cit. note 35, p.90. and 97.

${ }^{45}$ M.W. Baron, P. Pettit and M. Slote. 1997. Three Methods of Ethics. Oxford. Blackwell: 8.

${ }^{46}$ I. Kant, op.cit. note 39, p.70.

${ }^{47}$ See http://www.neweconomics.org/gen/democs.aspx (accessed 29.06.2007).

${ }^{48}$ C. Sunstein. 2003. The Law of Group Polarization. In Debating Deliberative Democracy. J. S. Fishkin and P. Laslett, eds. Malden, MA. Blackwell: 81.

${ }^{49}$ From Project Information on Tom Shakespeare's web page:

http://www.ncl.ac.uk/peals/research/currentprojects/project/849 (accessed 29.06.2007) 
GSP Genomics, Society and Policy

online 2007, Vol.3, No.1, pp.1-16

${ }^{50} \mathrm{M}$. Levitt and S. Weldon. A well placed trust? Public perceptions of the governance of DNA databases. Critical Public Health 2005; 15 (4): 313.

${ }^{51}$ Ibid, p.314.

${ }^{52}$ Ibid, p.320. Similar findings from focus group interviews on genetics are reported in A. Kerr, S.

Cunningham-Burley and A. Amos. The new genetics and health: Mobilizing lay expertise. Public

Understanding of Science 1998; 7 (1): 41-60. 